\title{
ATIVIDADE ENZIMÁTICA DE ISOLADOS DE RIZÓBIA NATIVOS DA AMAZÔNIA CENTRAL CRESCENDO EM DIFERENTES NÍVEIS DE ACIDEZ ${ }^{1}$
}

\author{
Arlem Nascimento de OLIVEIRA ${ }^{2}$, Luiz Antonio de OLIVEIRA ${ }^{3, *}$, \\ Jerusa Souza ANDRADE ${ }^{4}$, Aloisio Freitas CHAGAS JÚNIOR ${ }^{2}$
}

\begin{abstract}
RESUMO
A importância das bactérias conhecidas como rizóbia no estabelecimento de leguminosas tem sido amplamente reconhecida. Porém, poucas são as informações referentes ao perfil enzimático dessas bactérias benéficas. O estudo objetivou investigar a influência do pH do meio sólido sobre a atividade enzimática de rizóbios nativos da Amazônia Central. Essa triagem constitui o primeiro passo no processo de seleção de microorganismos benéficos, como produtores de enzimas de aplicação biotecnológica. Nesse estudo, 64 isolados de rizóbia foram testados para a produção extracelular de amilase, lipase, pectinase e protease, em meio YMA modificado. Excetuando a atividade pectinolítica, todas as outras enzimas (amilase, lipase e protease) foram detectadas nos isolados investigados. Dois isolados (INPA R-975 e INPA R-926) exibiram atividades amilolíticas, lipolíticas e proteolíticas. Os índices enzimáticos amilolíticos e proteolíticos variaram significativamente entre os isolados e as condições de pH do meio de cultura. De maneira geral, as maiores atividades amilolíticas e proteolíticas foram exibidas pelos isolados INPA R-957, INPA R-915B e INPA R-991 em pH 6,5. O isolado INPA R-957 também se mostrou amilolítico e proteolítico nos pHs 5,0 e 8,0. Esse estudo mostrou que alguns rizóbios nativos da Amazônia representam fontes promissoras de amilase e protease de uso biotecnológico, sobretudo na tecnologia de alimentos. Palavras-chave: amilase, lipase, pectinase, protease, feijão caupi, soja.
\end{abstract}

\section{SUMMARY}

ENZYMATIC ACTIVITY OF NATIVE CENTRAL AMAZONIAN RHIZOBIA STRAINS GROWN IN DIFFERENT LEVELS OF ACIDITY. The importance of rhizobia bacteria in the establishment of legume plants has been widely recognized. However, information is scarce regarding the enzymatic profiles of these beneficial bacteria. The objective of this study was to investigate the influence of $\mathrm{pH}$ of solid medium on enzymatic activity of native Central Amazonian rhizobia strains. This screening constitutes the first step in selecting beneficial microorganisms as enzyme producers. In this study, 64 strains of rhizobia were screened for extracellular amylolytic, lipolytic, pectinolytic and proteolytic activities on modified YMA. With the exception of pectinolytic activity, the other enzymatic activity groups (amylase, lipase and protease) were found in the strains investigated. Two isolates (INPA R-975 and INPA R-926) exhibited amylolytic, lipolytic and proteolytic activities. The activity levels of the amylases and proteases varied significantly among strains of rhizobia and among $\mathrm{pH}$ conditions. In general, the highest amylase and protease activities were presented by isolates INPA R-957, INPA R-915B and INPA R-991 at pH 6.5. The INPA R-957 isolate also showed amylolytic and proteolytic activities at pH 5.0 and 8.0. This study revealed several Central Amazonian rhizobia strains as promising sources of amylase and protease for biotechnological applications, especially in food technology.

Keywords: amylase, lipase, pectinase, protease, cowpea, soybean.

\section{1 - INTRODUÇÃO}

As enzimas são proteínas vitais que catalisam reações bioquímicas com grande especificidade, sendo capazes de aumentar em até $10^{14}$ vezes algumas reações, sem requerer condições extremas de $\mathrm{pH}$, pressão e temperatura. Além de formarem a base do sistema metabólico dos organismos vivos, essas proteínas proporcionam enormes oportuni-

\footnotetext{
${ }^{1}$ Recebido para publicação em 8/6/2005. Aceito para publicação em 23/1/2006 (001547)

${ }^{2}$ Doutorandos em Biotecnologia pela Universidade Federal do Amazonas (Ufam)

E-mail:arlem@inpa.gov.br

${ }^{3}$ Pesquisador do Instituto Nacional de Pesquisas da Amazônia (Inpa), professor da Ufam e da Universidade do Estado do Amazonas (UEA) e bolsista do Conselho Nacional de Desenvolvimento Científico e Tecnológico ( $\mathrm{CNPq}$ )

Inpa - Avenida André Araújo, 2.936 - Petrópolis - Caixa Postal 478

CEP 69011-970 - Manaus (AM)

E-mail: liuzoli@inpa.gov.br

${ }^{4}$ Pesquisadora do Inpa e professora da Ufam e do Centro Universitário Nilton Lins (Unilton Lins)

*A quem a correspondência deve ser enviada
}

dades às indústrias por efetuarem conversões biocatalíticas finas, eficientes e mais econômicas [10]. De acordo com algumas estimativas, o uso de enzimas industriais no cenário mundial cresceu de US\$ 1 bilhão em 1995 [9] para US\$ 1,5 bilhão em 2000 [20], podendo atingir US\$ 2 bilhões em 2005 [10].

Apesar de as enzimas ocorrerem amplamente em plantas e animais, as de origem microbiana representam as melhores fontes devido à sua ampla diversidade bioquímica e susceptibilidade à manipulação genética [2]. Depois dos antibióticos, as enzimas são os produtos mais explorados pela indústria biotecnológica, as quais são utilizadas em larga escala nas indústrias têxtil (amilase, celulase, pectinase), papel (lipase, xilanase, oxidoredutase), detergente (celulase, lipase, protease), couro (lipase, protease) e de alimento (pectinase, lipase, amilase, protease) [14, 30], entre outras.

As enzimas microbianas extracelulares podem ser produzidas em meio líquido ou sólido. O uso de meio sólido, ao contrário do meio líquido, permite a triagem de uma grande quantidade de microorganismos [26], além de 
possibilitar uma rápida detecção de enzimas específicas [27, 28, 26]. A melhor diferenciação quimiotaxonômica de muitos isolados microbianos é um outro aspecto vantajoso do meio sólido em relação ao meio líquido [11].

Programas para selecionar novas fontes microbianas para a produção de enzimas estão crescendo em todas as partes do planeta. As nitrogenase e hidrogenase presentes nas bactérias comumente referidas como rizóbia, são enzimas chaves na fixação biológica do nitrogênio atmosférico pelas plantas leguminosas e, portanto, as de maior interesse biotecnológico na área agronômica. Porém, não se pode negligenciar as potencialidades de uso dessas bactérias como fontes de outras enzimas de reconhecido valor industrial, como é o caso das amilases, lipases, pectinases e proteases [14, 30].

Uma das exigências para que um microorganismo possa ser fonte de enzimas de uso potencial nas indústrias de alimentos, é que ele não cause qualquer tipo de problema ao consumo humano. E nesse contexto enquadram-se as bactérias rizobiais, uma vez que até o momento não se tem qualquer relato de toxidez causada por esse grupo de bactérias ao organismo humano.

Inúmeros fatores de natureza biológica ou físico-química podem influenciar no número e atividade enzimática dos microorganismos. De acordo com SANOMIYA \& NAHAS [26], a freqüência de bactérias amilolíticas, celulolíticas, proteolíticas e ureolíticas é significativamente influenciada pelo pH do solo. Em meio de cultivo sólido, MACCHERONI JR. et al. [18], estudando o efeito do pH do ambiente na secreção das enzimas amilase, celulase, lipase, pectinase e protease por isolados de Colletotrichum, observaram para todas as enzimas, um padrão de secreção dependente do $\mathrm{pH}$ ambiental. Esses relatos deixam claro que o pH é uma importante variável tanto na atividade como nos mecanismos que controlam a síntese e secreção das enzimas extracelulares. Portanto, levando em consideração a escassez de estudos referentes ao potencial biotecnológico desses microorganismos como fontes de enzimas de interesse alimentar, objetiva-se avaliar a influência do $\mathrm{pH}$ do meio sólido sobre as atividades amilolítica, lipolítica, pectinolítica e proteolítica de isolados de rizóbia nativos da Amazônia Central.

\section{2 - MATERIAL E MÉTODOS}

\section{1 - Fontes de inóculo de rizóbia e cultivo das plantas armadilhas}

As amostras de solos foram obtidas em propriedades rurais dos municípios de Careiro da Várzea e Manacapuru, ambos no Estado do Amazonas. Nessas propriedades foram coletadas amostras de solos de várzea e terra preta de índio como fontes potenciais de inóculo de rizóbia. Do ponto de vista químico, esses solos são considerados extremamente férteis. As coletas foram feitas a partir das rizosferas de cultivos de feijão, mandioca, couve, jerimum, pepino, quiabo, além de algumas gramíneas, a uma profundidade máxima de $10 \mathrm{~cm}$.
Para capturar os rizóbios presentes nas amostras de solo, foi realizado um experimento em casa de vegetação, usando-se como substrato uma proporção de areia estéril (lavada e autoclavada a $121^{\circ} \mathrm{C}$ por $1 \mathrm{~h}$ ) e solo inóculo na proporção de 30:1, ou seja, 900 g de areia estéril para 30 g de solo inóculo. Foram utilizadas plantas de feijão caupi e soja como espécies armadilhas, com três repetições para cada amostra de solo. As sementes dessas leguminosas foram previamente colocadas em imersão no álcool (95\% por $3 \mathrm{~min}$ ) visando reduzir sua tensão superficial, para em seguida serem imersas em hipoclorito de sódio ( $1 \%$ por 3 min). Ao final desses tratamentos, as sementes receberam lavagens sucessivas com água estéril (autoclavada a $121^{\circ} \mathrm{C}$ por $30 \mathrm{~min}$ ).

As sementes isentas de contaminantes foram semeadas em copos de plástico (700 mL) previamente preparados. A irrigação foi feita com água estéril e, após uma semana do início da germinação das sementes, as plântulas receberam a cada dois dias $50 \mathrm{~mL}$ de solução nutritiva [24], contendo em mg L-1 de água estéril: $\mathrm{Ca}\left(\mathrm{NO}_{3}\right)_{2}, 29 ; \mathrm{CaSO}_{4} \cdot 2 \mathrm{H}_{2} \mathrm{O}, 150$; $\mathrm{MgSO}_{4} .7 \mathrm{H}_{2} \mathrm{O}, 125 ; \mathrm{K}_{2} \mathrm{HPO}_{4} .3 \mathrm{H}_{2} \mathrm{O}, 100 ;$ FeEDTA, 6,3; $\mathrm{KCl}$, 1,$36 ; \mathrm{H}_{3} \mathrm{BO}_{3}, 1,26 ; \mathrm{MnSO}_{4} . \mathrm{H}_{2} \mathrm{O}, 0,626 ; \mathrm{ZnSO}_{4} .7 \mathrm{H}_{2} \mathrm{O}, 0,136$; $\left(\mathrm{NH}_{4}\right)_{6} \mathrm{Mo}_{7} \mathrm{O}_{24} \cdot 4 \mathrm{H}_{2} \mathrm{O}, 0,136 ; \mathrm{CuSO}_{4} .5 \mathrm{H}_{2} \mathrm{O}, 0,125$. Guando necessário, o pH dos meios foi ajustado para $\mathrm{pH}$ 6,5 com solução de $\mathrm{KOH}$ a 5\%. Depois de 40 dias de semeadura, os nódulos foram colhidos, lavados em água corrente e guardados na geladeira antes do isolamento das bactérias.

\section{2 - Isolamento dos rizóbios e condiçóes de cultivo das bactérias}

No laboratório de Microbiologia de Solo da Coordenação de Pesquisas em Ciências Agronômicas do Instituto Nacional de Pesquisas da Amazônia (CPCA/Inpa), os nódulos obtidos como anteriormente descrito foram assepticamente lavados com álcool (95\% por 10 s), seguindo uma desinfestação superficial com hipoclorito de sódio ( $1 \%$ por $4 \mathrm{~min}$ ) e lavagens sucessivas com água estéril.

Em seguida, os nódulos foram esmagados e a suspensão obtida semeada pelo método de estrias na superfície de placas contendo o meio de cultura YMA [32], encerrando em $\mathrm{g} \mathrm{L}^{-1}$ de água estéril: $\mathrm{MgSO}_{4} .7 \mathrm{H}_{2} \mathrm{O}, 0,2$; $\mathrm{NaCl}, 0,1$; extrato de levedura, 0,4; manitol, 10; $\mathrm{KH}_{2} \mathrm{PO}_{4}, 0,4 ; \mathrm{K}_{2} \mathrm{HPO}_{4}$, $0,1, \mathrm{pH} 6,5)$. Após um período máximo de oito dias de incubação a $28^{\circ} \mathrm{C}$, a massa de bactérias formada sobre o meio foi novamente inoculada com auxílio de uma alça de platina, no mesmo meio de cultura, visando obtenção de colônias puras. Uma caracterização parcial das bactérias foi realizada segundo VINCENT [32] e, ao final dessa etapa, elas foram codificadas como diferentes isolados de rizóbia. Até a execução dos testes enzimáticos, as bactérias foram conservadas em meio YMA a $4^{\circ} \mathrm{C}$.

\section{3 - Meios de cultivo e processos de triagem enzimática}

Para detecção das atividades enzimáticas extracelulares, utilizou-se o meio YMA com modificações, substituindo-se 
o manitol por outras fontes de carbono (mesma concentração, $1 \%$ ) requeridas nos ensaios enzimáticos.

\subsection{1 - Atividade amilolítica}

Os isolados de rizóbia foram testados quanto à habilidade em hidrolisar amido de milho (maizena) como única fonte de carbono. Após quatro dias de incubação a $28^{\circ} \mathrm{C}$, as colônias na placa de Petri foram reveladas com solução de tintura de iodo. Uma zona amarela suave ao redor da colônia em contraste com o meio azul indicou resultado positivo para a atividade amilolítica [6].

\subsection{2 - Atividade lipolítica}

A produção de lipase extracelular foi registrada após 14 dias de crescimento das bactérias em meio contendo azeite de oliva como substrato de carbono e incubação a $28^{\circ} \mathrm{C}$. Para a revelação da atividade lipolítica, as placas contendo colônias foram mantidas durante $12 \mathrm{~h}$ na geladeira para induzir a formação de cristais de cálcio, caracterizado pela presença de halo transparente em volta da colônia [27]. Quando não foi possível a visualização do halo de degradação, as placas foram irradiadas com luz ultravioleta (359 $\mathrm{nm}$ ), nas quais a observação de fluorescência ao redor da colônia caracterizou a presença da enzima.

\subsection{3 - Atividade proteolítica}

A habilidade das bactérias em hidrolisar proteínas foi testada em meio contendo caseína como única fonte de carbono. Para melhor visualização do halo de proteólise, após quatro dias de incubação a $28^{\circ} \mathrm{C}$, as colônias nas placas foram reveladas usando-se solução de ácido acético a 5\% [27]. Uma região transparente ao redor da colônia em contraste com a superfície opaca do meio na placa indicou atividade proteolítica.

\subsection{4 - Atividade pectinolítica}

Na determinação da atividade pectinolítica foi utilizada a pectina cítrica como substrato de carbono. Após um período de sete dias de crescimento das bactérias a $28^{\circ} \mathrm{C}$, as colônias foram reveladas adicionando-se solução de $\mathrm{HCl} 5 \mathrm{~N}$. A presença de um halo claro em volta da colônia sugeriu a degradação da pectina cítrica [6].

\section{4 - Determinação da atividade enzimática extracelular}

As medições dos diâmetros dos halos de hidrólise e da colônia foram realizadas com paquímetro ( $\mathrm{mm}$ ), colocado no reverso das placas de Petri, nos períodos de incubação de quatro (amilase e protease), sete (pectinase) e 14 dias (lipase) a $28^{\circ} \mathrm{C}$, no escuro. A atividade enzimática extracelular foi avaliada mediante a relação entre o diâmetro médio do halo de degradação e o diâmetro médio da colônia e expressa como índice enzimático [11]. Desse modo, quanto maior o índice maior é a atividade enzimática no meio.

\section{5 - Delineamento experimental}

Utilizou-se o delineamento estatístico inteiramente casualizado, nos seguintes arranjos fatoriais: 20x3 (isolados de rizóbia amilolíticos e condições de pH: 5,0, 6,5 e 8,0); e 24x3 (isolados de rizóbia proteolíticos e condições de pH). Quanto às bactérias lipolíticas, não foi possível montar um desenho fatorial em virtude de testes preliminares acusarem tal atividade somente em pH 6,5.

Os dados de índice enzimático foram submetidos às análises de variância, e nos casos em que foram constatadas variações significativas entre os fatores estudados, as médias foram discriminadas pelo teste de Tukey $(\mathrm{p}<0,01)$, utilizando-se o Sistema de Análise Estatística (ESTAT 2.0) [7].

\section{3 - RESULTADOS E DISCUSSÃo}

Foram isolados e testados 64 tipos morfológicos distintos de rizóbia, dos quais, 35,9\% exibiram habilidade em hidrolisar caseína, 29,7\% amido de milho e 4,9\% óleo de oliva (Tabela 1). Contudo, nenhum dos isolados demonstrou habilidade em degradar pectina cítrica, contradizendo alguns relatos da ocorrência de pectinases em estirpes de Rhizobium sp. isoladas de leguminosas de regiões temperadas [3, 12, 19]. Nesses trabalhos, os autores observaram em todas as estirpes uma pronunciada atividade pectinolítica em meio ágar pectina, incluindo variantes não nodulíferas de $R$. trifolii e R. phaseoli. Por outro lado, HUBBELL et al. [12], estudando a capacidade de 11 estirpes tropicais de Rhizobium sp. em degradar pectina, constataram baixos níveis ou ausência de pectinases em experimentos conduzidos em meio sólido em placas de Petri.

Apesar de poucos estudos publicados sobre esse assunto, é provável que, devido à baixa atividade pectinolítica em rizóbios tropicais [12], seja mais difícil sua detecção em meio de cultura sólido, sobretudo num período de incubação inferior a de outros relatos, no qual as estirpes investigadas foram incubadas por até 21 dias [12, 19]. De modo geral, as bactérias isoladas dos nódulos de feijão caupi mostraram um complexo enzimático ligeiramente mais diversificado em relação aos isolados bacterianos de soja. Das quatro enzimas hidrolíticas investigadas, os

TABELA 1 - Número de isolados de rizóbia com atividades hidrolíticas em meio YMA modificado

\begin{tabular}{lccc}
\hline Atividades & $\begin{array}{c}\text { Isolados positivos de feijão } \\
\text { caupi (\%) }\end{array}$ & $\begin{array}{c}\text { Isolados positivos de soja } \\
\text { (\%) }\end{array}$ & $\begin{array}{c}\mathbf{N}^{\circ} \text { de isolados positivos/ } \\
\text { total isolados }\end{array}$ \\
\hline Amilolítica & $18 / 46(39,1)$ & $1 / 18(5,6)$ & $19 / 64$ \\
Lipolítica & $3 / 46(6,5)$ & $0 / 18(0,0)$ & $3 / 64$ \\
Pectinolítica & $0 / 46(0,0)$ & $0 / 18(0,0)$ & $0 / 64$ \\
Proteolítica & $17 / 46(37,0)$ & 6,9 & 29,7 \\
\hline
\end{tabular}


isolados INPA R-975 e INPA R-926 exibiram atividades para três: amilase, lipase e protease (Tabela 2). Essa versatilidade enzimática tem sido mostrada por outros grupos de bactérias do solo [26].

TABELA 2 - Produção de enzimas hidrolíticas por isolados de rizóbia em meio YMA modificado

\begin{tabular}{|c|c|c|c|c|}
\hline Isolados & Amilase & Lipase & Pectinase & Protease \\
\hline INPA R-921 & + & - & - & - \\
\hline INPA R-990* & + & - & - & - \\
\hline INPA R-937 & + & - & - & - \\
\hline INPA R-902 & + & - & - & + \\
\hline INPA R-973* & + & + & - & - \\
\hline INPA R-987 & + & - & - & + \\
\hline INPA R-923* & + & - & - & - \\
\hline INPA R-975 & + & + & - & + \\
\hline INPA R-926* & + & + & - & + \\
\hline INPA R-911* & + & - & - & + \\
\hline INPA R-988* & + & - & - & + \\
\hline INPA R-957 & + & - & - & + \\
\hline INPA R-936* & - & - & - & + \\
\hline INPA R-908* & + & - & - & - \\
\hline INPA R-938* & + & - & - & + \\
\hline INPA R-960* & + & - & - & - \\
\hline INPA R-968A* & + & - & - & + \\
\hline INPA R-927 & + & - & - & + \\
\hline INPA R-16 ${ }^{* *}$ & - & - & - & + \\
\hline INPA R-991** & + & - & - & + \\
\hline INPA R-915B* & + & - & - & + \\
\hline INPA R-922* & + & - & - & - \\
\hline INPA R-968B ${ }^{*}$ & + & - & - & - \\
\hline INPA R-965 & - & - & - & + \\
\hline INPA R-979 & - & - & - & - \\
\hline INPA R-989* & - & - & - & + \\
\hline INPA R-901 & - & - & - & + \\
\hline INPA R-971 & - & - & - & + \\
\hline INPA R-972* & - & - & - & + \\
\hline INPA R-993A** & - & - & - & + \\
\hline INPA R-993** & + & - & - & + \\
\hline INPA R-994** & - & - & - & + \\
\hline INPA R-995 & - & - & - & + \\
\hline
\end{tabular}

De acordo com os dados da Tabela 1,37\% das bactérias que induziram nodulação no feijão caupi apresentaram atividade proteolítica. O mesmo perfil enzimático foi observado em mais de $33 \%$ dos isolados de rizóbia de soja, ratificando alguns relatos anteriores de produção dessa hidrolase por algumas estirpes de Rhizobium [20, 9]. Quanto à habilidade em hidrolisar amido de milho, 39,1\% das bactérias isoladas de feijão caupi manifestaram essa capacidade em meio YMA modificado. Por outro lado, entre os 18 isolados obtidos dos nódulos de soja, apenas um demonstrou tal habilidade enzimática (Tabelas 1 e 2).

ALLISON [1] demonstrou que o suprimento de carboidrato é um dos principais fatores envolvido na formação e desenvolvimento de nódulos em leguminosas. Em plantas de feijão comum e soja, estudos têm registrado acúmulos de trealose, maltose e sacarose nos nódulos radiculares dessas leguminosas [29, 8]. Enzimas correspondentes para esses dissacarídeos também têm sido detectadas nos nódulos [29,13]. A acumulação de amido também parece ser importante durante a nodulação e amiloplastos têm sido encontrados acumulados em nódulos e em células corticais de alfafa nodulada por Rhizobium meliloti [4]. Esse fato foi confirmado a partir de uma observação que um mutante não-nodulífero de Bradyrhizobium japonicum acumulou amido em nódulos de soja [22].

Em adição, trabalho conduzido por BERTHELOT \& DELMOTTE [5] sugeriu uma possível participação das glicosidases (maltase, amilases, trealase e celulase) no estabelecimento da simbiose intracelular entre leguminosas e rizóbias. Esses estudos corroboram os resultados sobre a ocorrência de atividade amilolítica observados no presente trabalho.

Nas condições experimentais estudadas, a atividade lipolítica foi observada apenas nas bactérias que induziram nodulação nas plantas de feijão caupi (Tabela 2).

A literatura atual registra várias metodologias para se avaliar a habilidade dos microorganismos em produzir enzimas extracelulares em meio sólido. De acordo com alguns autores [23, 17, 27], entre as variáveis que determinam e viabilizam a escolha do método mais apropriado de triagem microbiana incluem a relação direta entre o tamanho do halo e a capacidade degradativa dos microorganismos. LEALEM \& GASHE [16, citado por 27] sugerem um índice enzimático $\geq 2,0$ para considerar um microorganismo como produtor potencial de enzimas em meio sólido. No presente estudo, em se tratando da atividade amilolítica, o índice enzimático encontrado variou significativamente entre os diferentes isolados de rizóbia e o pH do meio sólido; os dados revelaram também uma interação significativa entre esses dois fatores (Tabela 3), enaltecendo os resultados observados por outros autores [15, 18, 26].

TABELA 3 - Influência do pH sobre os índices enzimáticos amilolíticos* dos isolados de rizóbia em meio YMA modificado ${ }^{1}$

\begin{tabular}{|c|c|c|c|c|}
\hline \multirow{2}{*}{ Isolados } & \multicolumn{3}{|c|}{$\mathrm{pH}$} & \multirow{2}{*}{$\begin{array}{l}\text { Médias/ } \\
\text { Isolados }\end{array}$} \\
\hline & 5,0 & 6,5 & 8,0 & \\
\hline INPA R-921 & 1,4 a E & 1,5 a CDEF & 1,5 a B & $1,5 \mathrm{~cd}$ \\
\hline INPA R-990 & $0,0 \mathrm{~b} \mathrm{~F}$ & 1,2 a $E F G$ & 0,0 b C & $0,4 \mathrm{f}$ \\
\hline INPA R-902 & 1,5 a DE & 1,3 b CDEFG & 0,0 c C & $0,9 \mathrm{e}$ \\
\hline INPA R-973 & $0,0 \mathrm{~b} \mathrm{~F}$ & 1,4 a CDEF & 0,0 b C & $0,5 \mathrm{f}$ \\
\hline INPA R-987 & $0,0 \mathrm{~b} F$ & 2,1 a B & 0,0 b C & $0,6 \mathrm{f}$ \\
\hline INPA R-923 & $0,0 \mathrm{~b} \mathrm{~F}$ & 1,1 a FG & 0,0 b C & $0,4 \mathrm{f}$ \\
\hline INPA R-975 & 1,8 b CDE & 2,1 a B & 1,3 c BC & $1,7 \mathrm{~cd}$ \\
\hline INPA R-926 & $0,0 \mathrm{~b} F$ & 3,1 a $A$ & 0,0 b C & $1,0 \mathrm{e}$ \\
\hline INPA R-988 & $2,5 \mathrm{~b} A B$ & 2,8 a A & 0,0 с C & $1,8 \mathrm{c}$ \\
\hline INPA R-957 & 2,8 a $A$ & 2,8 a $A$ & 2,6 a A & $2,8 \mathrm{a}$ \\
\hline INPA R-908 & $0,0 \mathrm{~b} F$ & 1,3 a CDEFG & 0,0 b C & $0,4 \mathrm{f}$ \\
\hline INPA R-986 & $0,0 \mathrm{~b} F$ & 1,4 a CDEF & 0,0 b C & $0,5 \mathrm{f}$ \\
\hline INPA R-960 & $1,4 a b E$ & 1,3 b CDEFG & 1,7 a B & $1,5 \mathrm{~cd}$ \\
\hline INPA R-968A & $1,5 a b \mathrm{DE}$ & 1,3 b CDEFG & 1,6 a B & $1,5 \mathrm{~cd}$ \\
\hline INPA R-927 & $0,0 \mathrm{~b} \mathrm{~F}$ & 1,4 a CDEF & 1,6 a B & $1,0 \mathrm{e}$ \\
\hline INPA R-991 & 2,8 a $A$ & 1,8 b BC & 2,8 a A & $2,5 a b$ \\
\hline INPA R-915B & $2,1 \mathrm{~b} \mathrm{BC}$ & $2,2 \mathrm{ab} B$ & 2,5 a A & $2,3 b$ \\
\hline INPA R-922 & 1,9 a BCD & 1,8 a BC & 1,5 b B & $1,8 \mathrm{c}$ \\
\hline INPA R-968B & $0,0 \mathrm{~b} F$ & $0,0 \mathrm{~b} \mathrm{H}$ & 1,5 a B & $0,5 \mathrm{f}$ \\
\hline Médias/pH & $1,0 \mathrm{~B}$ & $1,7 \mathrm{~A}$ & $1,0 \mathrm{~B}$ & - \\
\hline
\end{tabular}

${ }^{1}$ Médias de três repetições - Médias seguidas pelas mesmas letras minúsculas na horizontal (médias dos pHs do meio dentro de cada isolado rizóbia) e maiúsculas na vertical (médias dos isolados rizóbia dentro de cada $\mathrm{pH}$ do meio), não diferem entre si pelo teste de Tukey $(\mathrm{p}<0,01)$. ${ }^{*}$ Os valores dos índices enzimáticos representam a relação entre o diâmetro médio do halo de degradação e diâmetro médio da colônia 
Ao avaliar os índices enzimáticos amilolíticos dos diferentes isolados de rizóbia (valor médio de hidrólise do amido nos três níveis de $\mathrm{pH}$ ), observou-se que apenas os isolados INPA R-957, INPA R-991 e INPA R-915B expressaram valores superiores a 2,0 (Tabela 3). Por outro lado, a interação entre fatores indica que outras bactérias podem ser consideradas boas produtoras de amilases, como é o caso dos isolados INPA R-988, INPA R-987, INPA R-975 e INPA R-926, que demonstraram, com exceção do INPA R-988, índices enzimáticos maiores do que 2 em meio ligeiramente ácido ( $\mathrm{pH}$ 6,5).

Essa constatação pode estar relacionada às condições edáficas, das quais as bactérias foram inicialmente isoladas (pHs 4,3 a 6,2). Em outros estudos, esse fato tem sido igualmente observado para outros microorganismos do solo $(15,6)$. Quando incubados em meio com pH 6,5, os isolados de rizóbia exibiram a maior média de atividade amilolítica, reforçando a idéia de que esse pode ser o $\mathrm{pH}$ preferencial de crescimento e produção de amilases por algumas bactérias da região.

Os diferentes pHs do meio sólido não influenciaram a atividade amilolítica das bactérias INPA R-921, INPA R-957, INPA R-960, INPA R-968A e INPA R-915B, cujos índices enzimáticos em meio alcalino foram $\geq 1,5$. Esses dados mostram a eficiência dessas bactérias em hidrolisar amido de milho em ambientes ácidos e alcalinos. Vale ressaltar que no ambiente alcalino, dentre os isolados citados anteriormente, apenas INPA R-957 e INPA R-915B podem ser considerados bons produtores de amilases, pois seus índices enzimáticos foram superiores a 2,0 (Tabela 3).

Contrariamente aos encontrados no presente estudo, MACCHERONI JR. et al. [18] não detectaram atividade amilolítica em Colletotrichum crescendo em pH 8,0. Esse fato pode estar relacionado com a natureza acidófila do fungo. Nesse estudo, o registro de atividades amilolíticas em uma ampla variação de $\mathrm{pH}$ sugere a possibilidade de uso dessas enzimas nos mais variados campos biotecnológicos, sobretudo na indústria do amido [30].

A atividade lipolítica foi registrada apenas em pH 6,5, confirmando em parte os relatos de Maccheroni Jr. et al. [18], que observaram ainda a secreção dessa enzima em ambiente alcalino. No presente trabalho, os índices enzimáticos lipolíticos dos isolados INPA R-926, INPA R-975 e INPA R-973 foram estatisticamente iguais e inferiores a 2,0 , logo não devem ser considerados como bons produtores de lipase.

A atividade proteolítica dos rizóbios investigados variou de 0 a 6,7 , resultando em diferenças significativas entre os fatores isolados e condições de $\mathrm{pH}$ do meio (Tabela 4). Essa interação significativa confirma os estudos de MACCHERONI JR. et al. [18], conforme os quais o pH do meio é uma importante variável na regulação da produção de protease por isolados de Colletotrichum. Analisando o índice enzimático nas diferentes condições de $\mathrm{pH}$, constatou-se que os isolados INPA R-957, INPA R-915B, INPA R-972 e INPA R-991 mostraram valores maiores do que
2,0, porém, sem diferirem significativamente entre si. A atividade proteolítica dos isolados crescendo em $\mathrm{pH}$ 6,5 de uma maneira geral foi estatisticamente superior em relação aos índices registrados nas duas outras condições de $\mathrm{pH}$ (Tabela 4).

TABELA 4 - Influência do pH sobre os índices enzimáticos proteolíticos* dos isolados de rizóbia em meio YMA modificado

\begin{tabular}{|c|c|c|c|c|}
\hline \multirow{2}{*}{ Isolados } & \multicolumn{3}{|c|}{$\mathrm{pH}$} & \multirow{2}{*}{$\begin{array}{l}\text { Médias/ } \\
\text { Isolados }\end{array}$} \\
\hline & 5,0 & 6,5 & 8,0 & \\
\hline INPA R-989 & 0,0 b D & 1,5 a EF & $0,0 \mathrm{~b} \mathrm{~B}$ & $0,5 \mathrm{de}$ \\
\hline INPA R-988 & 1,2 a BC & 1,7 a EF & $0,0 \mathrm{~b} B$ & $1,0 \mathrm{~cd}$ \\
\hline INPA R-911 & 0,0 b D & 1,6 a EF & $0,0 \mathrm{~b} \mathrm{~B}$ & $0,5 \mathrm{de}$ \\
\hline INPA R-957 & 3,4 a A & 2,4 b DE & $2,1 \mathrm{~b} \mathrm{~A}$ & $2,6 a$ \\
\hline INPA R-965 & 0,0 b D & 2,4 a DE & $0,0 \mathrm{~b} B$ & 0,8 cde \\
\hline INPA R-987 & 0,0 b D & 3,5 a BC & $0,0 \mathrm{~b} \mathrm{~B}$ & 1,2 bc \\
\hline INPA R-926 & 0,0 b D & 1,7 a EF & $0,0 \mathrm{~b} \mathrm{~B}$ & 0,6 cde \\
\hline INPA R-901 & 0,0 b D & 1,3 a $F$ & $0,0 \mathrm{cB}$ & $0,5 \mathrm{de}$ \\
\hline INPA R-986 & 0,0 b D & 2,8 a $C D$ & $0,0 \mathrm{~b} \mathrm{~B}$ & $0,9 \mathrm{cde}$ \\
\hline INPA R-915B & 1,0 b C & 6,7 a A & $0,0 \subset B$ & $2,6 a$ \\
\hline INPA R-971 & 0,0 b D & 2,4 a DE & 2,4 a A & $1,6 b$ \\
\hline INPA R-972 & $0,0 \mathrm{cD}$ & 4,4 a B & $2,3 \mathrm{~b} \mathrm{~A}$ & $2,2 \mathrm{a}$ \\
\hline INPA R-968 & 0,0 b D & 1,6 a EF & $0,0 \mathrm{~b} B$ & $0,5 \mathrm{de}$ \\
\hline INPA R-922 & 1,2 a BC & 0,0 b G & $0,0 \mathrm{~b} B$ & $0,4 \mathrm{e}$ \\
\hline INPA R-902 & 1,3 a $B C$ & 0,0 b G & $0,0 \mathrm{~b} \mathrm{~B}$ & $0,5 \mathrm{de}$ \\
\hline INPA R-975 & 1,9 a BC & 0,0 b G & $0,0 \mathrm{~b} B$ & 0,6 cde \\
\hline INPA R-927 & 2,1 a B & $0,0 \mathrm{~b}$ G & $0,0 \mathrm{~b} B$ & 0,7 cde \\
\hline INPA R-996 & $1,1 \mathrm{a} C$ & 0,0 b G & $0,0 \mathrm{~b} B$ & $0,4 \mathrm{e}$ \\
\hline INPA R-991 & 3,6 a A & 2,2 b DEF & $1,5 \mathrm{cA}$ & $2,4 \mathrm{a}$ \\
\hline INPA R-993B & 0,0 b D & 1,7 a EF & $0,0 \mathrm{~b} \mathrm{~B}$ & 0,6 cde \\
\hline INPA R-994 & 0,0 b D & 2,1 a DEF & $0,0 \mathrm{~b} \mathrm{~B}$ & 0,7 cde \\
\hline INPA R-995 & 0,0 b D & 1,5 a EF & $0,0 \mathrm{~b} \mathrm{~B}$ & $0,5 \mathrm{de}$ \\
\hline INPA R-993A & 0,0 b D & 2,4 a $D E$ & $0,0 \mathrm{~b} \mathrm{~B}$ & $0,8 \mathrm{cde}$ \\
\hline Médias/pH & $0,7 \mathrm{~B}$ & $1,9 \mathrm{~A}$ & $0,4 \mathrm{C}$ & - \\
\hline
\end{tabular}

${ }^{1}$ Médias de três repetições - Médias seguidas pelas mesmas letras minúsculas na horizontal (médias dos pHs do meio dentro de cada isolado rizóbia) e maiúsculas na vertical (médias dos isolados rizóbia dentro de cada $\mathrm{pH}$ do meio), não diferem entre si pelo teste de Tukey $(\mathrm{p}<0,01)$. * Os valores dos índices enzimáticos representam a relação entre o diâmetro médio do halo de degradação e o diâmetro médio da colônia

Dentre as bactérias consideradas produtoras de proteases, INPA R-991, INPA R-957 e INPA R-927 expressaram as maiores atividades em pH 5,0. Por sua vez, os isolados INPA R-915B, INPA R-972, INPA R-987, INPA R-986, INPA R-965, INPA R-993A e INPA R-994 exibiram os maiores valores em $\mathrm{pH}$ 6,5. Vale acrescentar, ainda, que nesse $\mathrm{pH}$ o isolado INPA R-915B apresentou o maior índice enzimático registrado no presente estudo (Tabela 4). O isolado INPA R-971 foi o único a manifestar máxima atividade proteolítica sob condição alcalina, apesar desse valor não diferir do índice registrado em $\mathrm{pH}$ 6,5. Ainda que estatisticamente inferior aos índices enzimáticos anotados em ambiente ácido, o isolado INPA R-972 também pode ser considerado proteolítico em meio alcalino (Tabela 4).

Muitas proteases comerciais, principalmente de caráter neutro e alcalino, são produzidas por bactérias do gênero Bacillus [25]. As proteases neutras de bactérias são ativas em $\mathrm{pH}$ variando de 5,0 a 8,0, tendo relativamente baixa termotolerância. Devido à sua taxa intermediária de reação, as proteases neutras produzem menos amargor em alimentos protéicos hidrolisados do que as de origem animal e, 
por essa razão, são valiosas para o uso nas indústrias de alimentos [25]. Embora esse estudo não aborde aspectos cinéticos das enzimas, a habilidade exibida por alguns isolados nativos de rizóbia em produzir níveis "altos de proteases” em meio ácido e alcalino, é um forte indício de que essas bactérias são fontes potenciais promissoras de proteases de aplicação biotecnológica, especialmente no campo da tecnologia de alimentos.

\section{4 - CONCLUSÕES}

Os resultados do presente estudo demonstram que cerca de um terço dos isolados de rizóbia apresenta atividade amilolítica e proteolítica em meio YMA modificado, com o maior número de isolados com esses perfis enzimáticos sendo obtidos a partir dos nódulos de feijão caupi.

Os nódulos de feijão caupi foram a melhor fonte de bactérias lipolíticas e a atividade pectinolítica não foi anotada em nenhum dos 64 isolados investigados.

Esse estudo também demonstrou que as atividades amilolíticas e proteolíticas dos diferentes isolados estão sujeitas às variações de $\mathrm{pH}$ do meio, com freqüência e atividade enzimática sendo maiores em pH 6,5.

Os isolados INPA R-957, INPA R-915B e INPA R-991 exibiram os maiores índices amilolíticos e proteolíticos, enquanto INPA R-975 e INPA R-926 foram os de maior diversificação enzimática, produzindo, concomitantemente, amilase, lipase e protease em meio YMA modificado.

\section{5 - REFERÊNCIAS BIBLIOGRÁFICAS}

[1] ALLISON, F.E. Carbohydrate supply as a primary factor in legume symbiosis. Soil Science, v. 39, p. 123-143, 1935.

[2] ALTAMIRANO, M.M.; BLACKBURN, J.M.; AGUAYO, C.; FERSHT, A.R. Directed evolution of new catalytic activity using the alpha/beta-barrel scaffold. Nature, v. 403, n. 6.770, p. 617-622, 2000.

[3] ANGLE, J.S. Pectic and proteolytic enzymes produced by fast and slow-growing soybean rhizobia. Soil Biology and Biochemistry, v. 18, n. 1, p. 115-116, 1986.

[4] ARDOUREL, M.; DEMONT, N.; DEBELLÉ, F.; MAILLET, F.; DE BILLY, F.; PROMÉ, J.C.; DÉNARIÉ, J.; TRUCHET, G. Rhizobium meliloti lipooligosaccharide nodulation factors: different structural requirements for bacterial entry into target root hair cells and induction of plant symbiotic developmental responses. Plant Cell, v. 6, n. 10, p. 1.357-1.374, 1994.

[5] BERTHELOT, K.; DELMOTTE, F.M. Purification and Characterization of an $\propto$ - Glucosidase from Rhizobium sp. (Robinia pseudoacacia L.) Strain USDA 4.280. Applied and Environmental Microbiology, v. 65, n. 7, p. 2.907-2.911, 1999.

[6] BUZZINI, P.; MARTINI, A. Extracellular enzymatic activity profiles in yeast and yeast-like strains isolated from tropical environments. Journal of Applied Microbiology, v. 93, n. 6, p. 1.020-1.025, 2002.

[7] ESTAT 2.0. SISTEMA DE ANÁLISE ESTATÍSTICA. Jaboticabal, Polo Computacional - Departamento de Ciências Exatas. Unesp, 1992.
[8] FARÍAS-RODRÍGUEZ, R.; MELLOR, R.B.; ARIAS, C.; PEÑA-CABRIALES, J.J. The accumulation of trehalose in nodules of several cultivars of common bean (Phaseolus vulgaris) and its correlation with resistance to drought stress. Physiologia Plantarum, v. 102, n. 3, p. 353-359, 1998.

[9] GLENN, A.R.; DILWORTH, M.J. The uptake and hydrolysis of disaccharides by fast-and slow-growing species of Rhizobium. Archives of Microbiology, v. 129, p. 233-239, 1981.

[10] GODFREY, T.; WEST, S.I. Introduction to industrial enzymology. In: GODFREY, T. (Ed.). Industrial Enzymology. $2^{\text {nd }}$ ed., Macmillan Press, p. 120-138, London, 1996.

[11] HANKIN, L.; ANAGNOSTAKIS, S.L. The use of solid media for detection of enzymes production by fungi. Mycologia, v. 67, p. 597-607, 1975.

[12] HUBBELL, D.H.; MORALES, V.M.; UMALLI-GARCIA, M. Pectolytic Enzymes in Rhizobium. Applied and Environmental Microbiology, v. 35, n. 1, p. 210-213, 1978.

[13] KINNBACK, A.; WERNER, D. Glucosidases $(\propto$ e $\beta$ ) and trehalase $(\propto)$ in the peribacteroid space and the bacteroid periplasm of Glycine max root nodules. Plant Science, v. 77, n. 1, p. 47-55, 1991.

[14] KIRK, O.; BORCHERT, T.V.; FUGLSANG, C.C. Industrial enzyme applications. Current Opinion in Biotechnology, v. 13, n. 4, p. 345-351, 2002.

[15] LEAKE, J.R.; READ, D.L. Proteinase activity in mycorrhizal fungi. I. The effect of extracellular $\mathrm{pH}$ on the production and activity od proteinase by ericoid endophytes from soils of contrasted pH. New Phytologist, v. 115, p. 243-250, 1990.

[16] LEALEM, F.; GASHE, B.A. Amylase production by a gram-positive bacterium isolated from fermenting tef. (Eraglostis tef.). Journal of Applied Bacteriology, v. 77, p. 348-352, 1994.

[17] LIN, J.E.; CHANG, D.C.N.; SHEN, G.J. Correlations among several screening methods used for identifying wood-decay fungi that can degrade toxic chemicals. Biotechniques, v. 5, n. 4, p. 275-280, 1991.

[18] MACCHERONI JR., W.; ARAÚJO, W.L.; AZEVEDO, J.L. Ambient pH-regulated enzyme secretion in endophytic and pathogenic isolates of the fungal genus Colletotrichum. Scientia agricola, v. 61, n. 3, p. 298-302, 2004.

[19] MATEOS, P.F.; JIMENEZ-ZURDO, J.L.; CHEN, J.; SQUARTINI, A.S.; HAACK, S.K.; MARTINEZMOLINA, E.; HUBBELL, D.H.; DAZZO, F.B. Cellassociated pectinolytic and cellulolytic enzymes in Rhizobium leguminosarum biovar trifolii. Applied and Environmental Microbiology, v. 58, n. 7, p. 1.816-1.822, 1992.

[20] MARTINEZ-MOLINA, E.; MORALES, V.M.; HUBBELL, D.H. Hydrolytic enzymes production by Rhyzobium. Applied and Environmental Microbiology, v. 38, p. 1.186-1.188, 1979.

[21] MCCOY, M. Novozymes emerges. Chemical \& Engineering News, v. 19, p. 23-25, 2000.

[22] MÜLLER, J.; STAEHELIN, C.; BOLLER, T.; WIEMKEN, A. Carbohydrate pools in nodules of "nonnodulating" and "supernodulating" soybean (Glycine max L. Merr. cv. Bragg) mutants. Plant Physiology, v. 145, p. 759$762,1995$. 
[23] NETO, J.A.; CUNHA, B.C.A. Método rápido para a triagem de fungos amilolíticos e seus mutantes. Revista de Microbiologia, v. 18, p. 264-268, 1987.

[24] OLIVEIRA, L.A. Competitive ability of Rhizobiun leguminosarum bv. phaseoli strains. Minnesota, 1988. 125 p. Ph.D. thesis - University of Minnesota, United State of America.

[25] RAO, M.B.; TANKSALE, A.M.; GHATGE, M.S.; DESHPANDE, V.V. Molecular and biotechnological aspects of microbial proteases. Microbiology and Molecular Biology Reviews, v. 62, n. 3, p. 597-635, 1998.

[26] SANOMIYA, L.T.; NAHAS, E. Microorganismos produtores de hidrolases envolvidos nas transformações dos compostos do carbono e do nitrogênio do solo. Ciência Rural, v. 33, n. 5, p. 835-842, 2003.

[27] STAMFORD, T.L.M.; ARAÚJO, J.M.; STAMFORD, N.P. Atividade enzimática de microorganismos isolados do jacatupé (Pachyrhizus erosus L. Urban). Ciência e Tecnologia de Alimentos, v. 18, n. 4, p. 382-385, 1998.

[28] STRAUSS, M.L.A.; JOLLY, N.P.; LAMBRECHIS, M.G.; VAN RENSBURG, P. Screening for the production of extracellular hydrolytic enzymes by non-saccharomyces wine yeasts. Journal of Applied Microbiology, v. 91, n. 1 , p. 182-190, 2001 .
[29] STREETER, J.G. Enzymes of sucrose, maltose, and $\alpha, \alpha$ - trehalose catabolism in soybean root nodules. Planta, v. 155, n. 2, p. 112-115, 1982.

[30] VAN BEILEN, J.B. Enzyme technology: an overview. Current Opinion in Biotechnology, v. 14, n. 4, p. 338-344, 2002.

[31] VAN DER MAAREL, M.; VAN DER VEEN, B.; UITDEHAAG, H.; LEEMHUIS, H.; DIJKHUIZEN, L. Properties and applications of starch-converting enzymes of the $\alpha$-amylase family. Journal of Biotechnology, v. 94, n. 2, p. 137-155, 2002.

[32] VINCENT, J.M. A manual for the practical study of root-nodules bacteria. Brackwell Science Publication, Oxford, 159 p., 1970.

\section{6 - AGRADECIMENTOS}

Os autores agradecem ao Conselho Nacional de Desenvolvimento Científico e Tecnológico (CNPq) (Processo: 474007/2003-0), pela concessão de recursos financeiros à realização desse trabalho. O primeiro autor mostra-se grato, também, à Superintendência da Zona Franca de Manaus (Suframa), pela concessão da bolsa de doutorado. 